\title{
Human lung cancer cells express functionally active Toll-like receptor 9
}

\author{
Daniel Droemann*1, Dirk Albrecht ${ }^{1,2}$, Johannes Gerdes², Artur J Ulmer ${ }^{2}$, \\ Detlev Branscheid ${ }^{3}$, Ekkehard Vollmer ${ }^{4}$, Klaus Dalhoff ${ }^{5}$, Peter Zabel ${ }^{1,5}$ and \\ Torsten Goldmann ${ }^{4}$
}

\begin{abstract}
Address: ${ }^{1}$ Medical Clinic, Research Center Borstel, D-23845 Borstel, Germany, ${ }^{2}$ Department of Immunology and Cell Biology, Research Center Borstel, D-23845 Borstel, Germany, ${ }^{3}$ Department for Thoracic Surgery, Krankenhaus Großhansdorf, D-22927 Großhansdorf, Germany, ${ }^{4}$ Clinical and Experimental Pathology, Research Center Borstel, D-23845 Borstel, Germany and ${ }^{5}$ Medical Clinic III, University of Lübeck, D-23538 Lübeck, Germany

Email: Daniel Droemann* - ddroemann@fz-borstel.de; Dirk Albrecht - dalbrecht@fz-borstel.de; Johannes Gerdes - jgerdes@fz-borstel.de; Artur J Ulmer - ajulmer@fz-borstel.de; Detlev Branscheid - branscheid@kh-grosshansdorf.de; Ekkehard Vollmer - evollmer@fz-borstel.de; Klaus Dalhoff - klaus.dalhoff@uni-luebeck.de; Peter Zabel - pzabel@fz-borstel.de; Torsten Goldmann - tgoldmann@fz-borstel.de

* Corresponding author
\end{abstract}

Published: 04 January 2005

Respiratory Research 2005, 6:I doi:10.1186/1465-992I-6-I
Received: 16 August 2004

Accepted: 04 January 2005

This article is available from: http://respiratory-research.com/content/6/I/I

(c) 2005 Droemann et al; licensee BioMed Central Ltd.

This is an Open Access article distributed under the terms of the Creative Commons Attribution License (http://creativecommons.org/licenses/by/2.0), which permits unrestricted use, distribution, and reproduction in any medium, provided the original work is properly cited.

\footnotetext{
Abstract

Background: $C_{p G}$-oligonucleotides (CpG-ODN), which induce signaling through Toll-like receptor 9 (TLR9), are currently under investigation as adjuvants in therapy against infections and cancer. CPG-ODN function as Th-I adjuvants and are able to activate dendritic cells. In humans TLR9 has been described to be strongly expressed in B-lymphocytes, monocytes, plasmacytoid dendritic cells and at low levels in human respiratory cells. We determined whether a direct interaction of bacterial DNA with the tumor cells themselves is possible and investigated the expression and function of TLR9 in human malignant solid tumors and cell lines. TLR9 expression by malignant tumor cells, would affect treatment approaches using CPG-ODN on the one hand, and, on the other hand, provide additional novel information about the role of tumor cells in tumor-immunology.

Methods: The expression of TLR9 in HOPE-fixed non-small lung cancer, non-malignant tissue and tumor cell lines was assessed using immunohistochemistry, confocal microscopy, in situ hybridization, RT-PCR and DNA-sequencing. Apoptosis and chemokine expression was detected by FACS analysis and the BioPlex system.

Results: We found high TLR9 signal intensities in the cytoplasm of tumor cells in the majority of lung cancer specimens as well as in all tested tumor cell lines. In contrast to this non-malignant lung tissues showed only sporadically weak expression. Stimulation of HeLa and A549 cells with CPG-ODN induced secretion of monocyte chemoattractant protein-I and reduction of spontaneous and tumor necrosis factor-alpha induced apoptosis.

Conclusions: Here we show that TLR9 is expressed in a selection of human lung cancer tissues and various tumor cell lines. The expression of functionally active TLR9 in human malignant tumors might affect treatment approaches using $C_{p}$ G-ODN and shows that malignant cells can be regarded as active players in tumor-immunology.
} 


\section{Background}

The Toll gene, the expression of one of it's relatives we are reporting here concerning human malignant tumors, originally was characterized for its role in specifying dorsoventral polarity of the Drosophila embryo[1]. Since homologues of Toll are also present in plants, mammalian toll-like genes are products of an ancient evolutionary process beginning before the separation of animals and plants [2]. Within the genome of Drosophila thus far nine toll-like genes were identified, ten different human tolllike genes are currently described. In contrast to Drosophila, the mechanisms taking place in mammalian embryogenesis concerning TLR are widely unknown. The discovery of immune function for Toll in Drosophila led to a new understanding of innate immunity mechanisms.

Human TLR recognize pathogen-derived products, also termed pathogen-associated molecular patterns (PAMP) [3]. These are bacterial lipoproteins (sBLP) [4], viral double stranded RNA/poly (I:C) [5], lipopolysaccharides (LPS) [6], flagellin [7] and bacterial DNA [8], which engage TLR2, TLR3, TLR4, TLR5 and TLR9, respectively. All functionally characterized TLR signal via the cytoplasmic Toll/interleukin-1 receptor domain (TIR) leading to activation of transcription factors like activator protein-1

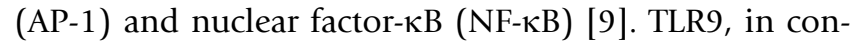
trast to the other TLR, is not located at the cell surface, but intracellularily and, therefore, inhibition of endocytosis or endosome formation completely ablates the effects of CpG-ODN [10].

Different studies show an immunostimulatory capacity of bacterial components which can mediate anti-tumor activity. The first reported use of such a therapy for a nonbacterial disease took place 1890, evaluating the antitumor activity of living streptococci directly injected into tumor masses [11]. Shimada demonstrated that bacterial DNA itself can stimulate the immune system [12]. Over the past years there has been an enormous increase in the understanding of the molecular and cellular effects of CpG-ODN [13], which have been found to function as Th- 1 adjuvants [14], and are able to activate dendritic cells [15]. This led to the idea to utilize CpG-ODN for induction of anti-tumor immune response as an adjuvant therapeutic strategy [16-18].

In order to characterize possible interactions between malignant cells and CpG-ODN, we investigated whether TLR9 is present in malignant tumors. A variety of malignant solid tumors and cell lines were tested for TLR9 expression; in addition, we examined direct effects of CpG-ODN upon apoptosis and chemokine production of tumor cells.

\section{Methods \\ Tissues}

Samples of human tumors and tumor-free tissues were obtained from lobectomies because of lung cancer. Tumor-free tissues were taken at least $5 \mathrm{~cm}$ away from the tumor-border. The specimens were fixed and paraffinembedded using the HOPE-technique [19]. Sections were cut, mounted, and deparaffinized as described elsewhere [20].

For increased comparability of the staining intensities in malignant and non malignant cells we additionally performed IHC on tumor-bearing and tumor free lung tissues which have been assembled on one slide by use of a mechanical tissue arrayer device (MTA1, Alphametrix, Germany).

\section{Cell culture}

A549 cells and HeLa cells were grown in $25 \mathrm{~cm}^{2}$ polystyrene flasks with Dulbecco's modified Eagle's medium DMEM (Sigma) with $10 \%$ heat-inactivated fetal calf serum (PAA Laboratories), $100 \mu \mathrm{g} / \mathrm{ml}$ penicillin $\mathrm{G}, 100$ $\mu \mathrm{g} / \mathrm{ml}$ streptomycin and $2 \mathrm{mM}$ L-glutamine (Sigma), maintained under $5 \% \mathrm{CO}_{2}$ by routine passage every 3 days. Cells were seeded in 35-mm dishes (Nunc).

For IHC cells were cytocentrifuged and treated by the HOPE-technique [21], the cell lines used were: A549, HeLa, NCI-H727, Jurkat, L428, CPC-N, Raji, H23, U937, H157, H125, L428, and DV90.

\section{Preparation of the probes}

Total RNA was extracted from lung tissues according to the manufacturer's recommendations (RNeasy, Qiagen). After destroying residual DNA with DNase (Invitrogen), cDNA was synthesized by reverse transcription [22]. PCR was performed targeting a $393 \mathrm{bp}$ fragment of human TLR9-mRNA (TLR9 forward: AAC TGG CTG TTC CTG AAG TC; TLR9 reverse: TGC CGT CCA TGA ATA GGA AG). PCR-products were separated on $2 \%$ agarose gels stained by ethidiumbromide. Cycle sequencing confirmed $100 \%$ identity with the human TLR9 wild-type-sequence. Probes were labeled with digoxigenin using High-Prime (Roche) according to the manufacturer's recommendations [23].

\section{ISH}

Hybridization, detection of signals and controls were carried out as previously described (concentration of probe 2 $\mathrm{ng} / \mu \mathrm{l}$, hybridization temperature $\left.46^{\circ} \mathrm{C}\right)[20,22]$.

\section{IHC}

Primary antibody (mouse anti-human TLR9, clone 26C593, Imgenex) was applied in a dilution of $1 / 100$ in PBS for $16 \mathrm{~h}$ at $4{ }^{\circ} \mathrm{C}$. Negative controls comprised omission of the primary antibody. Detection was performed by 
horseradish-peroxidase labeled streptavidine-biotin technique (LSAB2, Dako) [24].

\section{RT-PCR/Cell lines}

A549, HeLa, BEAS 2b, U937, and NCI-H727 cell lines were used. RT-PCR was performed like described above using TLR9 specific primers (forward: 5'CATGCCCTGCGCTTCCTATTCA; reverse: 5'TGGGCCAGCACAAACAGCGTCTT) spanning an amplicon of $260 \mathrm{bp}$. Mononuclear cells were included as positive control as well as RT-PCR targeting glyceraldehyde-3-phosphate dehydrogenase (GAPDH) (forward: GTCATCATCTCCGCCCCTTCTGC; reverse: GATGCCTGCTTCACCACCTTCTTG) (not shown). PCR-products were separated along with a molecular weight marker (MW8, Roche) using $2 \%$ agarose gels (Fig. 1).

\section{Transfection}

A549-cells were seeded in 35-mm glass bottom dishes (MatTek Corp.) overnight. Cells were transfected with GFP-huTLR9 using Polyfect (Qiagen) according to the manufacturer's instructions or incubated in medium.

\section{Confocal Microscopy}

Cells were washed in tris-buffered-saline, containing 0.2 $\%$ Tween 20 (TTBS), fixed with $4 \%$ paraformaldehyde in phosphate-buffered-saline (PBS) for $10 \mathrm{~min}$ on ice, and permeabilized with $0.25 \%$ Triton-X100 (Roche) in PBS for $10 \mathrm{~min}$. Cells were washed with TTBS, blocked with 10 $\%$ bovine-serum-albumine (BSA) in TBS for $20 \mathrm{~min}$, and incubated with primary antibody (clone 26C593, Imgenex) or isotype (Mouse IgG1, Jackson ImmunoResearch Laboratories) 1:150 in TBS $10 \%$ BSA for $30 \mathrm{~min}$. Cells were washed with TTBS, incubated for $30 \mathrm{~min}$ with Alexa-568/goat-anti-MouseIgG1 (Molecular Probes Inc.) 1:500 in TBS containing $10 \%$ BSA, and washed with TTBS. Counterstaining was achieved using TOTO-3 1:500 in TBS containing $10 \%$ BSA. Cells were washed with TTBS, fixed again as above, mounted and analyzed using a confocal laser microscope. The GFP-TLR9 plasmid was kindly provided by Terje Espevik, Trondheim, Norway.

\section{Treatment Protocols}

For CpG-ODN stimulation the M362 sequence was used in a concentration of $1 \mu \mathrm{M}$; as control M383 was used as described by Hartmann et al. [25] (MWG-Biotech). Human tumor necrosis factor-alpha (TNF- $\alpha$, Roche) in PBS containing $0.5 \%$ bovine serum albumin was added to the cultures in a concentration of $10 \mathrm{ng} / \mathrm{ml}$. CHX (Sigma) was dissolved in PBS and added in a concentration of $10 \mu \mathrm{M}$.

\section{Flow cytometry}

Annexin-V FITC apoptosis kit I and PE-conjugated active caspase-3 apoptosis kit I were used according to the man- ufacturer's instructions (BD Pharmingen). TLR9 antibody and isotype control (eBioscience, clone: eB72-1665) were stained after fixation and permeabilization using Intraprep (Beckmann Coulter) according to the manufacturer's instructions. Flowcytometric data (FACS Calibur) collected from 10,000 cells are reported as percentages of positive cells (Becton Dickinson).

\section{Cytokine assays}

Cell culture supernatant ( $50 \mu \mathrm{l}$ per sample) was analyzed using the Bio-Plex system and a Luminex 100TM analyzer (BioRad) according to manufacturer's instructions.

\section{Stimulation of tumor-tissues and RT-PCR}

Tissue blocks from lung cancer specimens (edge length approximately $0.5 \mathrm{~cm}$ ) were cultivated in RPMI 1640 at $37^{\circ} \mathrm{C}$ and $5 \% \mathrm{CO}_{2}$ for $24 \mathrm{~h}$, and either stimulated or not stimulated with $1 \mu \mathrm{M}$ of CpG-ODN (M362 sequence). These blocks from adjacent locations of the same lungtumors were fixed using the HOPE-technique and paraffin embedded. RT-PCR was carried out like described above using primers targeting human MCP-1 (forward: AAAGCACCAGTCAACTGGAC; reverse: AGCGCTTGGTGATGTGCTTT) resulting in a 149 bp PCR-product and GAPDH (forward: AGAACGGGAAGCTTGTCATC; reverse: TGCTGATGATCTTGAGGCTG) resulting in a 257 bp PCR-product. PCR products were separated on $2 \%$ agarose gels along with a molecular weight marker (pBR322-Msp1) and the results displayed in figure $4 \mathrm{~b}$.

\section{Results}

\section{Expression of TLR9 in malignant tumors}

To investigate the expression of TLR9 in human lung tumors and lung tumor cell lines we used the recently described HOPE-fixation method. HOPE-fixed [19] specimens showed superior preservation of morphology after in situ hybridization (ISH). The generation of TLR9-signals was achieved within 10 minutes, whereas unspecific signals were not detected in the control preparations. We found high signal intensities for TLR9 transcripts in the cytoplasm of tumor cells in the majority of lung cancer specimens. Immunohistochemistry (IHC) revealed strong TLR9 protein expression within tumor cells of tissues and cell lines. In contrast normal lung tissues sporadically showed weak expression of TLR9 mainly in cells revealing morphological characteristics of alveolar macrophages and alveolar epithelial cells as displayed in figure 1. Negative control specimens did not display signals. The results are summarized in table 1 ; some representative results of ISH and IHC are displayed in figure 1. To confirm the results obtained by ISH we analyzed TLR9-transcripts in tumor cell lines by RT-PCR. As shown in figure 1 , we found that all tumor cell lines indeed express TLR9. 

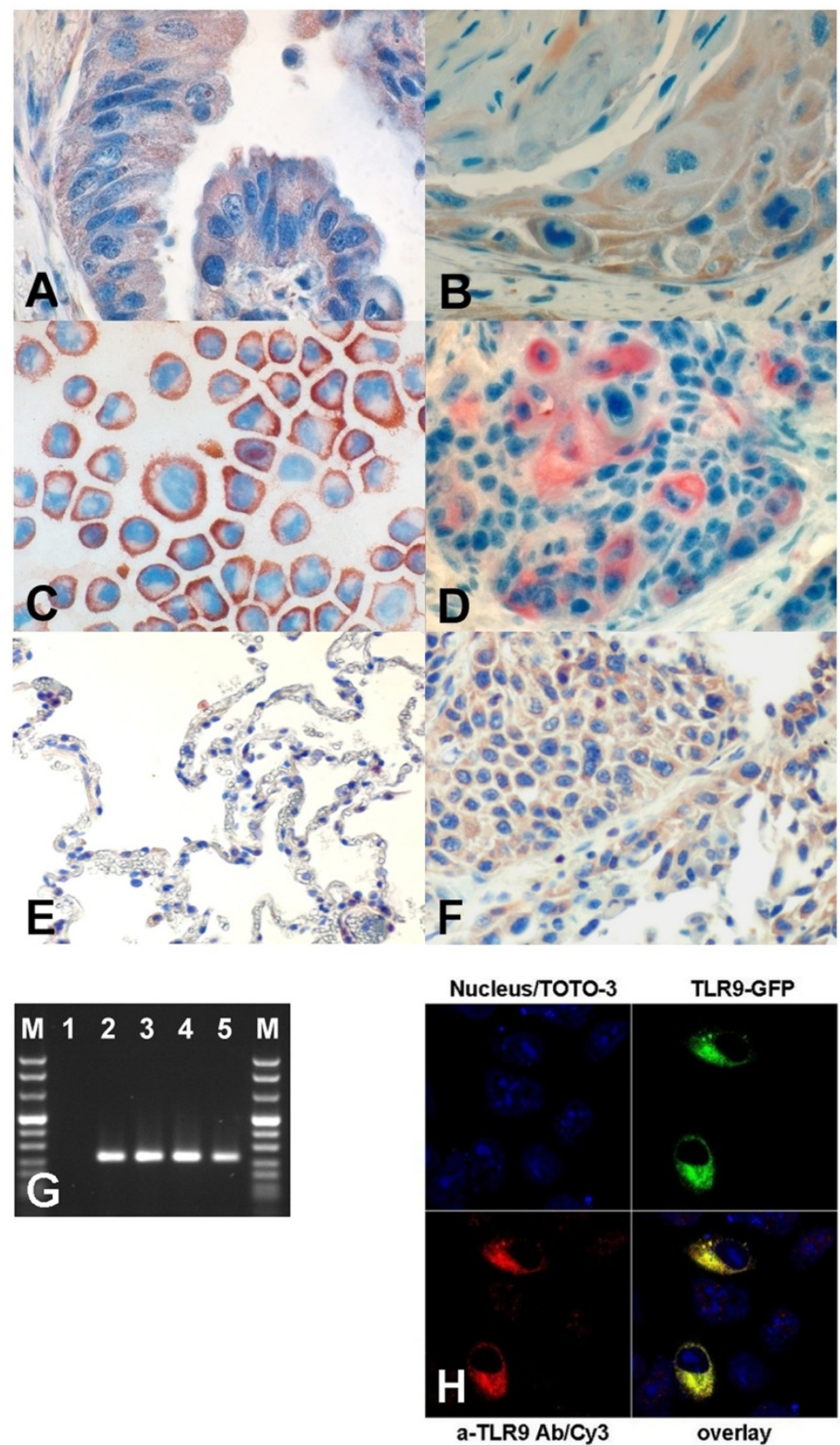

\section{Figure I}

Immunohistochemistry (IHC) (A-C) for TLR9 detected by a mouse monoclonal antibody. Adenocarcinoma of the lung (A). Squamous cell carcinoma of the lung (B). A549 cells (all $600 \times$ ) (C). In situ hybridization (ISH) targeting mRNA of human TLR9 with a digoxigenin-labeled DNA-probe in a squamous cell carcinoma of the lung $(600 \times)$ (D). Immunohistochemical staining of TLR9-expression-levels in nonmalignant (E) and malignant tissues (F) derived from the same lungs an stained by the use of tissue arrays. Results of RT-PCR targeting TLR9 in cell lines (G). M: molecular-weight marker (MW8, Roche). I: negative control; 2: A549; 3: NCl-H727; 4: BEAS 2b; 5: Mononuclear cells from a healthy human donor. Confocal laser microscopy of A549 cells transiently transfected with a GFP-TLR9 plasmid: Cytoplasmic expression of TLR9 is observable in all cells, while successful transfection led to overexpression of TLR9 resulting in bright GFP signals completely superimposed by the TLR9 antibody signal (H). Nuclear counterstain was performed with TOTO3. 

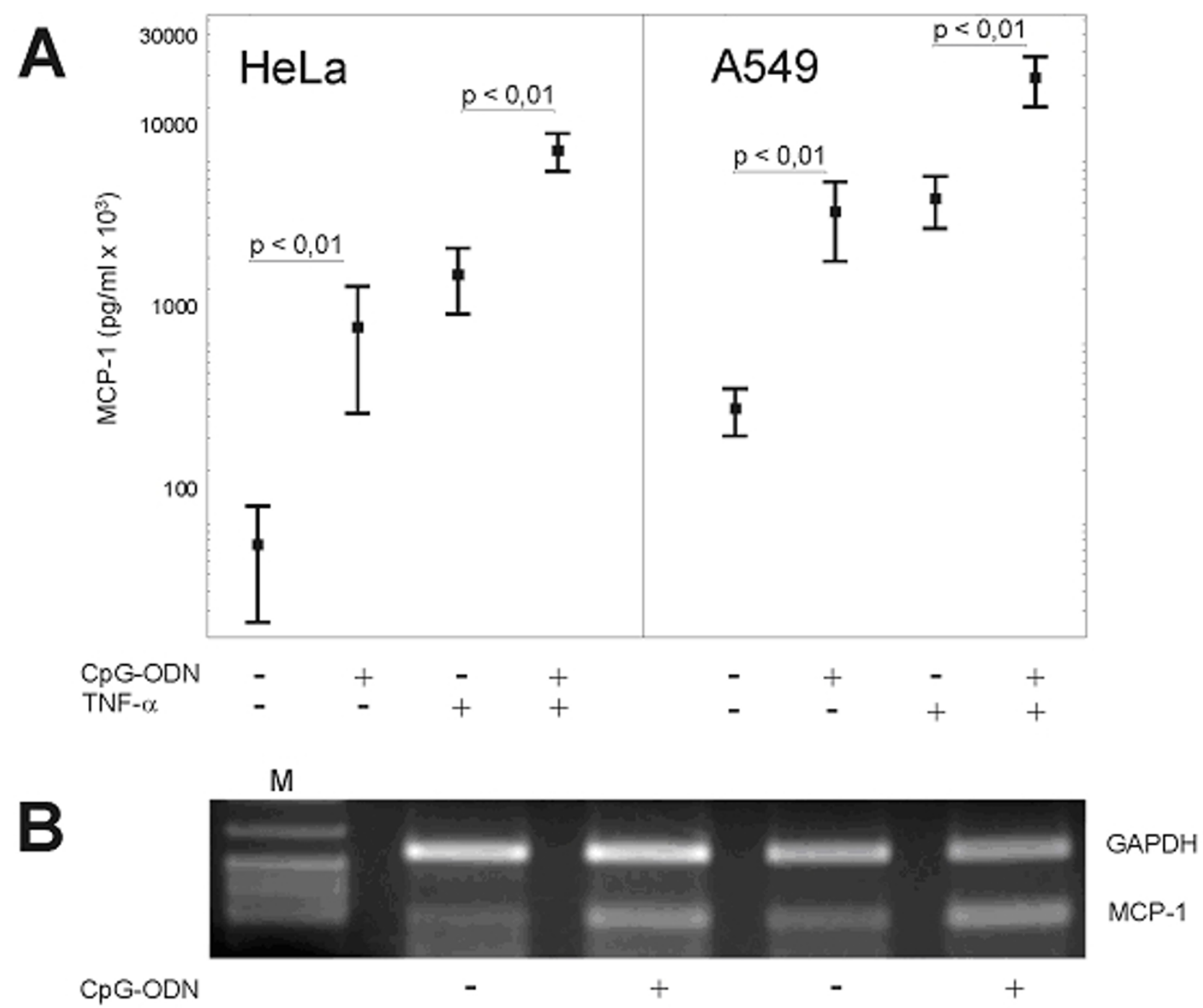

\section{Figure 4}

MCP-I secretion in response to CPG-ODN-stimulation in the presence or absence of TNF- $\alpha$ by HeLa and A549 cells (A). Data are expressed as the mean \pm SD $(n=6)$. Student's $t$ test was used for statistical analysis. RT-PCR targeting mRNA of MCP-I in human non-small cell lung cancer tissue stimulated with CpG-ODN for $24 \mathrm{~h}(\mathrm{~B})(\mathrm{M}=\mathrm{pBR} 322-\mathrm{Msp} /)$. Lanes 2 and 3 , as well as lanes 4 and 5 respectively show results of tissue samples from the same tumors either in the absence or presence of CpG-ODN.

A cytoplasmic localization of TLR9 was confirmed by confocal microscopy (fig. 1). This finding is in agreement with previous studies on the distribution of TLR9 in RAW264.7 cells [10]. Furthermore, immunostaining of GFP-TLR9 transfected A549 cells verified the specificity of the TLR9 antibody: Only those cells which were successfully transfected as demonstrated by the GFP-dependent fluorescence also stained brightly with the TLR9 antibody.
CPG-ODN stimulation reduces spontaneous and tumor necrosis factor-alpha (TNF- $\alpha$ )/Cycloheximide (CHX)induced apoptosis

The expression of TLR9 in tumor cells and cell lines rises up the question, whether this receptor is functional active in these cells. As shown in figure 2a, CpG-ODN decrease the rate of spontaneous and induced apoptosis in HeLa and A549 cells after treatment with TNF- $\alpha$ and CHX. 
Table I: Summarized results of immunohistochemistry (IHC) targeting TLR9 in tumor tissues and cell lines.

\begin{tabular}{llccc}
\hline Entity & $\mathbf{N}^{*}$ & No expression & Weak expression & Strong expression \\
\hline Adenocarcinoma of the lung & 21 & 1 & 7 & 13 \\
Squamous cell carcinoma of the lung & 23 & 1 & 0 & 8 \\
Large cell carcinoma of the lung & 3 & 0 & 2 & 1 \\
Cell lines** & 13 & 2 & 24 & 3 \\
Total & 60 & & 12 \\
\hline
\end{tabular}

* Number of analyzed specimens

** See methods
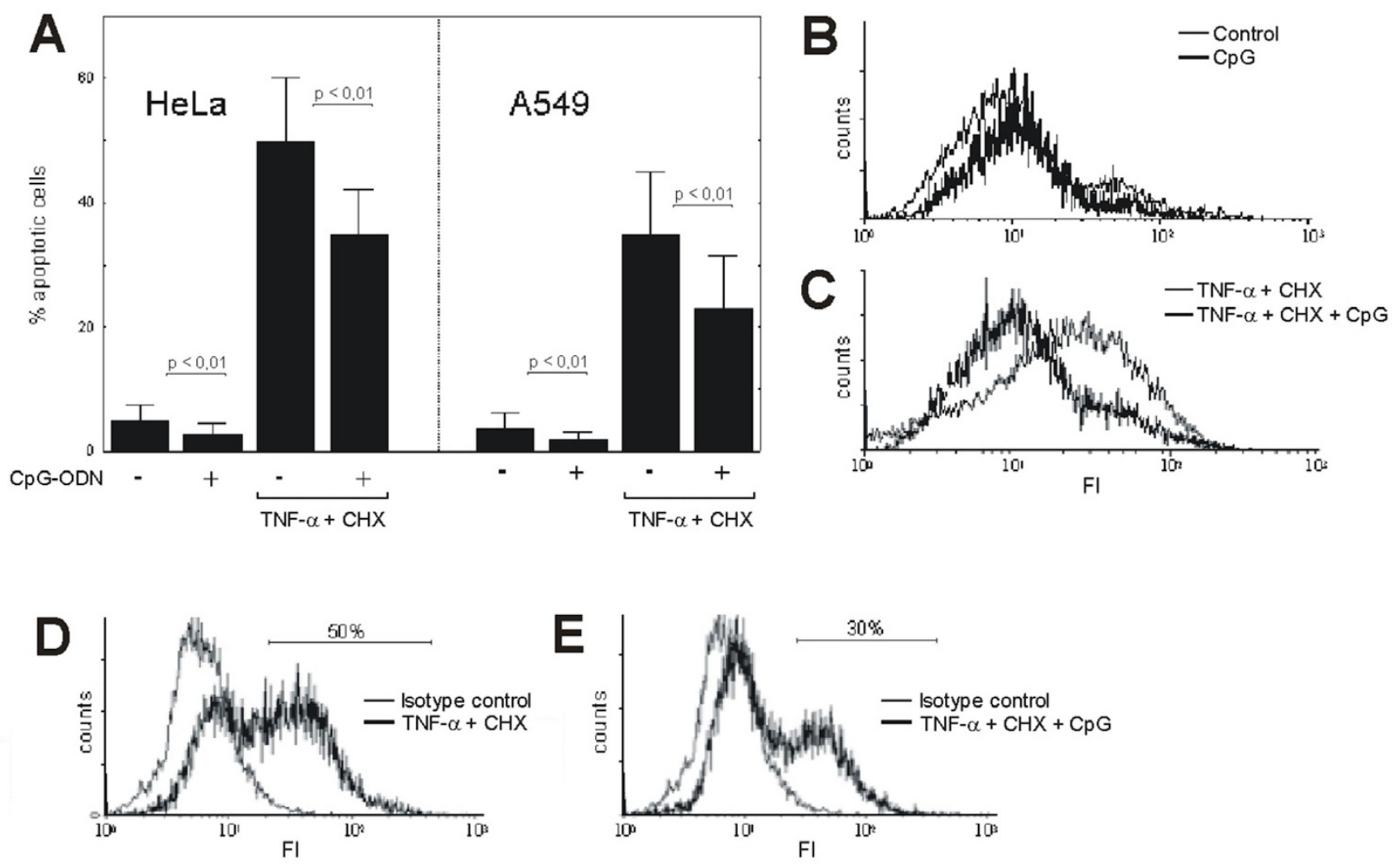

\section{Figure 2}

CpG-ODN-stimulation decreases apoptosis in HeLa and A549 cells. Cells were stained with Annexin-V after CpG-ODN-stimulation in the presence or absence of TNF- $\alpha$ and $\mathrm{CHX}$ after $24 \mathrm{~h}(\mathbf{A})$. Data are expressed as the mean \pm SD ( $n=6)$. Student's $t$ test was used for statistical analysis. Representative histograms are shown from experiments with HeLa cells after CpGODN-stimulation in the absence (B) or presence (C) of TNF- $\alpha$ and CHX. Caspase 3 expression in HeLa cells is shown after incubation with TNF- $\alpha$ and $\mathrm{CHX}$ (D). In the presence of CpG-ODN the expression is decreased (E). The percentage of positive cells in each sample is indicated. 

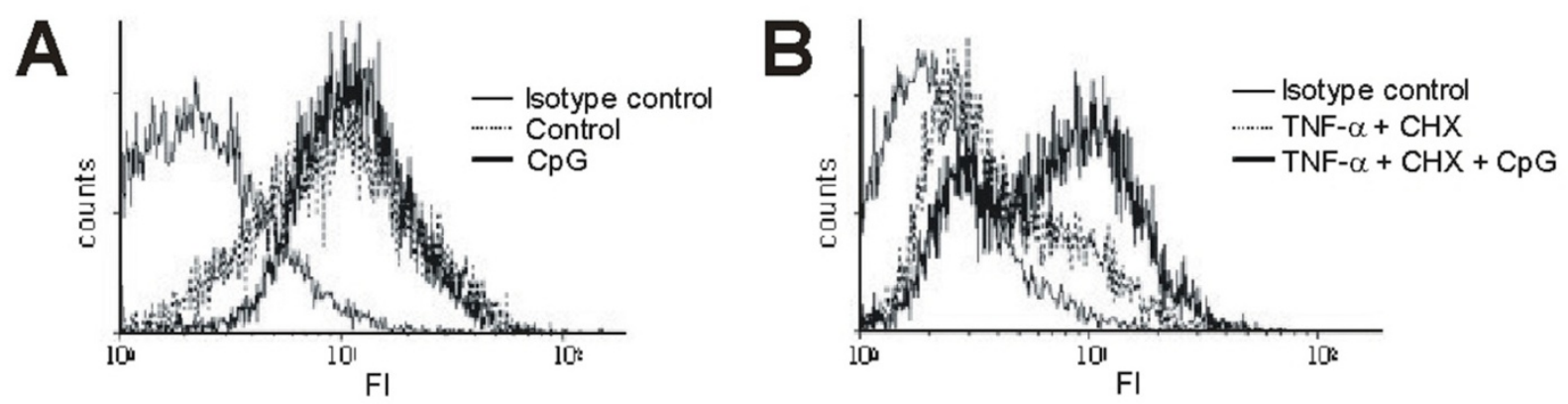

Figure 3

TLR9 expression after CpG-ODN-stimulation in HeLa cells: There is no difference in TLR9 expression with and without CpGODN-stimulation after $24 \mathrm{~h}$ (A). CpG-ODN partially inhibit downregulation of TLR9 which is induced by TNF- $\alpha$ and CHX (B). $\mathrm{FI}=$ fluorescence intensity.

Representative histograms demonstrate the detection of annexin in the presence or absence of CpG-ODN and TNF- $\alpha / C H X$ (Fig. 2b and 2c). The induction of apoptosis after stimulation with TNF- $\alpha / \mathrm{CHX}$ was further verified by the expression of active caspase 3 as shown in figure $2 \mathrm{~d}$. In the presence of CpG-ODN the expression was reduced analogous to the reduction of annexin-staining (Fig. 2e).

\section{Influence of induced apoptosis on TLR9 expression}

Here we investigated, whether CpG-ODN can modulate their own receptor. We found no differences in TLR9 expression with and without CpG-ODN stimulation. However, in the presence of TNF- $\alpha / \mathrm{CHX}$ the expression of TLR9 was strongly reduced, whereas CpG-ODN stimulation counteracted this downregulation (Fig. 3a and 3b).

Secretion of MCP-I in response to CPG-ODN and TNF- $\alpha$ In order to obtain further information about the functional activity of TLR9 in tumors we studied cytokine release upon CpG-ODN stimulation. The measurement of cytokines from stimulated HeLa and A549 cells revealed a significantly enhanced release of monocyte chemoattractant protein-1 (MCP-1) after $24 \mathrm{~h}$ of stimulation in response to CpG-ODN or TNF- $\alpha$ (Fig. 4a). The production was further enhanced when stimulated with a combination of CpG-ODN and TNF- $\alpha$ (Fig. 4a). There was no effect of CpG-ODN on TNF- $\alpha$ production (data not shown). To verify the induction of MCP-1 by CpG-ODN in cell lines we additionally analyzed human tumor tissues by RT-PCR; the results are shown in figure $4 \mathrm{~b}$. The relative amounts of RT-PCR-signals for MCP-1 in relation to GAPDH were higher in the specimens treated with CpG-
ODN if compared with the controls confirming the results obtained in cell culture experiments on the tissue level.

\section{Discussion}

By application of a novel fixation technique we specify for the first time the expression of TLR9 protein and mRNA in a selection of human non small cell lung cancer tissues as well as cell lines. Stimulation of the TLR-9 expressing cell lines A549 and HeLa with CpG-ODN showed a marked antiapoptotic effect. In addition, there was substantially enhanced release of MCP-1 from the cell lines upon CpGODN stimulation which was also shown in ex vivo experiments. We conclude the expression of a functionally active TLR9 in human malignant tumors.

The presence of molecules involved in ontogenesis e.g. the carcinoembryonic antigen (CEA) is frequently observed in malignant tumors suggesting a kind of "shift-back" towards earlier developmental stages [26]. The significance and underlying mechanisms of this phenomenon are poorly understood; nevertheless, the detection of such molecules is used for diagnostic purposes in cancer [27]. The role of TLR in mammalian embryogenesis is unknown, and thus far there is no evidence for an endogenous TLR9 ligand homologous to Spaetzle. Such a ligand could play a role for the activation of human TLR9. Whether the expression of TLR9 in human malignant cells takes advantage of TLR9-function in embryogenesis therefore remains unclear.

On the other hand TLR9 in malignant cells could have similar functions as in cells of the innate and adaptive 
immune system. In humans TLR9 has been described to be mainly expressed in B-lymphocytes, monocytes and plasmacytoid dendritic cells [28]. In addition Platz et al. reported a weak expression in respiratory epithelial cell lines and primary epithelial cells [29].

The CpG-ODN sequence M362 used in our study is known to potently activate TLR9-expressing immune cells in humans including plasmacytoid dendritic cells and B cells as shown by Hartmann et al. [25] B cells are induced to proliferate and secrete immunoglobulin in response to CpG-ODN, dendritic cells produce a wide array of cytokines and apoptosis is inhibited [30,31].

These mechanisms are both reflected in the results we obtained in our study after CpG-ODN stimulation of malignant cells:

Firstly, stimulation of the A549 and HeLa cells with CpGODN showed an antiapoptotic effect. This was demonstrated for spontaneous as well as induced apoptosis with TNF- $\alpha$ and CHX after $24 \mathrm{~h}$. Our observation is consistent with previous evidence in other cell lines. Yi et al. demonstrated antiapoptotic effects of CpG-ODN in a mouse B lymphoma cell line [32], and similar changes were described in chronic lymphocytic leukemia cells $[33,34]$. Previous data of systemic administration of bacterial DNA as a single agent in vivo showed anti-tumor effects. However, this anti-tumor effect appears to be effective indirectly and is related to enhanced NK cell activity. In a murine model of lymphoma the immunostimulatory effect of CpG-ODN was demonstrated to be responsible for the observed anti-tumor effects [35]. Carpentier et al. have shown that CpG-ODN in vivo induced rejection of neuroblastoma xenografts [36]. In contrast CpG-ODN had no effect on survival in mice inoculated with the 38C13 murine $\mathrm{B}$ cell lymphoma. However, a single injection of CpG-ODN enhanced the response to antitumor antibody therapy [37]. To what extent the antiapoptotic effects of CpG-ODN on tumor cells demonstrated in our study affect the tumorbiology in vivo requires further investigation.

Secondly, tumor cell lines (A549 and HeLa) stimulated with CpG-ODN showed strong secretion of the CC chemokine MCP-1. Furthermore a similar effect was observed in the investigated tumor tissues. Immunostimulatory properties together with anti-tumor activity of bacterial DNA were initially reported for a DNA fraction derived from mycobacteria by Tokunaga and coworkers [38]. It is known that such DNA induces enhanced production of various cytokines with anti-tumoral activity in NK cells, B cells, monocytes, macrophages and dendritic cells, such as TNF- $\alpha$, IL-12, and IFN- $\gamma$ [39]. In our study a substantial costimulatory effect in addition to CpG-ODN was achieved using TNF- $\alpha$. MCP-1 has various biological activities including the induction of increased cytotoxic activity of monocytes and NK cells. Transfection of MCP-1 into a human malignant glioma cell line tested on nude mice did not reduce the tumor mass but was associated with the infiltration of large numbers of NK cells and monocytes at the tumor site [40]. A further study by Nokihara et al. performed with transfection of the MCP-1 gene into human lung adenocarcinoma cells showed reduced systemic spread of transfected cells inoculated i.v. in NK cell-intact severe combined immunodeficient (SCID) mice. These findings suggest that locally produced MCP-1 suppresses tumor progression by a NK cell-mediated mechanism [41]. Thus, apart from the direct activation of immune cells, the effect of CpG-ODN stimulation on the secretion of MCP1 by TLR9 expressing tumor cells could possibly lead to anti-tumoral effects due to an increase of local MCP1 production which then might lead to attraction of immune cells. The costimulatory effect of TNF- $\alpha$ as demonstrated in vitro in this study could further enhance this scenario.

Regarding TLR9 expression in nonmalignant lung tissue our data confirm the findings of low TLR9 expression in respiratory cells of Platz et al. [29], who have been working on single cell preparations. However TLR9 expression was only seen sporadically weak in nonmalignant lung tissue.

Biological explanations for the TLR9 expression in malignant cells require further investigations. Three possibilities are conceivable: Either this could represent a bystander phenomenon, a side effect of a pathway functional to a different purpose. Secondly the upregulation of TLR9 could be beneficial to the tumor, promoting tumor cell survival. Thirdly, it even might help immune control strategies of the organisms an element of a pathway directing defense mechanisms against malignantly transforming cells. While the first possibility seems unlikely in the light of our findings of a functionality of the receptor in various in vitro and ex vivo experiments, our data provide evidence for the second as well as the third possibility; the sum effect of these two counteracting mechanisms in an in vivo setting can not be estimated from these experiments and could even differ from tumor entity to tumor entity.

\section{Conclusions}

In conclusion, we showed in a selection of samples that human malignant tumors express functionally active TLR9 and respond to CpG treatment with prolonged survival and chemokine release. This might influence the effects of CpG-ODN based anti-tumor therapies. Broad screening approaches will be worthwhile to further substantiate these initial results. 
While recent strategies in tumor-immunology mainly target a strengthening of the host-defense, we provide evidence that the malignant cells themselves can be regarded active players in the complex struggle between tumor and host. In any case CpG-ODN based anti-tumor therapies should be reconsidered in the light of our findings since CpG-ODN products are currently in Phase I/II clinical trials both as a monotherapy and as part of multidrug regimens.

\section{Author's contributions}

DD carried out the flow cytometry and cytokine assays and was involved in the design and coordination of the study and drafting the manuscript. DA and AJU carried out the confocal microscopy, RT-PCR with cell lines and were involved in drafting the manuscript. JG was involved in immunohistochemistry of cell lines and the design of the study. DB conducted the surgical part of the study. EV conducted the pathological part of the study and was involved in the design of the study. KD and PZ conducted the clinical part of the study and were involved in the design and coordination of the study. TG performed the immunohistochemistry, in situ hybridization and RT-PCR with tissues and conceived of the study. All authors read and approved the final manuscript.

\section{Acknowledgements}

The authors thank H. Kühl, D. Bubritzki, S. Adrian, J. Hofmeister and S. Ross for excellent technical assistance, Elvira Richter for sequencing the PCR-products and Maria Manoukian for help with the confocal microscopy.

\section{References}

I. Belvin MP, Anderson KV: A conserved signaling pathway: the Drosophila toll-dorsal pathway. Annu Rev Cell Dev Biol 1996, | 2:393-416.

2. Beutler B, Rehli M: Evolution of the TIR, tolls and TLRs: functional inferences from computational biology. Curr Top Microbiol Immunol 2002, 270: I-2I.

3. Medzhitov R, Janeway C Jr: Innate immunity. N Engl J Med 2000, 343(5):338-344.

4. Aliprantis AO, Yang RB, Mark MR, Suggett S, Devaux B, Radolf JD, Klimpel GR, Godowski P, Zychlinsky A: Cell activation and apoptosis by bacterial lipoproteins through toll-like receptor-2. Science 1999, 285(5428):736-739.

5. Alexopoulou L, Holt AC, Medzhitov R, Flavell RA: Recognition of double-stranded RNA and activation of NF-kappaB by Tolllike receptor 3. Nature 200I, 4I3(6857):732-738.

6. Poltorak A, He X, Smirnova I, Liu MY, Van Huffel C, Du X, Birdwell D, Alejos E, Silva M, Galanos C, Freudenberg M, Ricciardi-Castagnoli $\mathrm{P}$, Layton $\mathrm{B}$, Beutler $\mathrm{B}$ : Defective LPS signaling in $\mathrm{C} 3 \mathrm{H} / \mathrm{HeJ}$ and C57BL/IOSCCr mice: mutations in TIr4 gene. Science 1998 , 282(5396):2085-2088.

7. Hayashi F, Smith KD, Ozinsky A, Hawn TR, Yi EC, Goodlett DR, Eng JK, Akira S, Underhill DM, Aderem A: The innate immune response to bacterial flagellin is mediated by Toll-like receptor 5. Nature 2001, 410(6832): 1099-II03.

8. Hemmi H, Takeuchi O, Kawai T, Kaisho T, Sato S, Sanjo, Matsumoto M, Hoshino K, Wagner H, Takeda K, Akira S: A Toll-like receptor recognizes bacterial DNA. Nature 2000, 408(68 I3):740-745.

9. Muzio M, Natoli G, Saccani S, Levrero M, Mantovani A: The human toll signaling pathway: divergence of nuclear factor kappaB and JNK/SAPK activation upstream of tumor necrosis factor receptor-associated factor 6 (TRAF6). J Exp Med 1998, | 87(12):2097-210।.
10. Ahmad-Nejad P, Hacker H, Rutz M, Bauer S, Vabulas RM, Wagner H: Bacterial CpG-DNA and lipopolysaccharides activate Tolllike receptors at distinct cellular compartments. Eur J Immunol 2002, 32(7): 1958-1968.

II. Coley WB: The treatment of malignant tumors by repeated inoculations of erysipelas. With a report of ten original cases. 1893. Clin Orthop 1991:3-II.

12. Shimada $S$, Yano $O$, Tokunaga $T$ : In vivo augmentation of natural killer cell activity with a deoxyribonucleic acid fraction of BCG. Jpn J Cancer Res 1986, 77(8):808-816.

13. Steinman RM, Dhodapkar M: Active immunization against cancer with dendritic cells: the near future. Int J Cancer 200I, 94(4):459-473.

14. Roman M, Martin-Orozco E, Goodman JS, Nguyen MD, Sato Y, Ronaghy A, Kornbluth RS, Richman DD, Carson DA, Raz E: Immunostimulatory DNA sequences function as $T$ helper-Ipromoting adjuvants. Nat Med 1997, 3(8):849-854.

15. Sparwasser T, Vabulas RM, Villmow B, Lipford GB, Wagner H: Bacterial CpG-DNA activates dendritic cells in vivo: $T$ helper cell-independent cytotoxic $T$ cell responses to soluble proteins. Eur J Immunol 2000, 30( I 2):359 I-3597.

16. Heckelsmiller K, Beck S, Rall K, Sipos B, Schlamp A, Tuma E, Rothenfusser S, Endres S, Hartmann G: Combined dendritic cell- and CpG oligonucleotide-based immune therapy cures large murine tumors that resist chemotherapy. Eur J Immunol 2002, 32(I I):3235-3245.

17. Okamoto M, Sato M: Toll-like receptor signaling in anti-cancer immunity. J Med Invest 2003, 50(I-2):9-24.

18. Wooldridge JE, Weiner GJ: CpG DNA and cancer immunotherapy: orchestrating the antitumor immune response. Curr Opin Oncol 2003, I 5(6):440-445.

19. Olert J, Wiedorn KH, Goldmann T, Kuhl H, Mehraein Y, Scherthan $H$, Niketeghad F, Vollmer E, Muller AM, Muller-Navia J: HOPE fixation: a novel fixing method and paraffin-embedding technique for human soft tissues. Pathol Res Pract 200I, I 97 ( I 2):823-826.

20. Goldmann T, Wiedorn KH, Kuhl H, Olert J, Branscheid D, Pechkovsky D, Zissel G, Galle J, Muller-Quernheim J, Vollmer E: Assessment of transcriptional gene activity in situ by application of HOPE-fixed, paraffin-embedded tissues. Pathol Res Pract 2002, I 98(2):91-95.

21. Umland O, Ulmer AJ, Vollmer E, Goldmann T: HOPE fixation of cytospin preparations of human cells for in situ hybridization and immunocytochemistry. J Histochem Cytochem 2003, 5 I (7):977-980.

22. Droemann D, Goldmann T, Branscheid D, Clark R, Dalhoff K, Zabel $P$, Vollmer E: Toll-like receptor 2 is expressed by alveolar epithelial cells type II and macrophages in the human lung. Histochem Cell Biol 2003, I 1 9(2): 103-108.

23. Roche Molecular Biochemicals: Nonradioactive in situ hybridization application manual. Roche Diagnostics, Boehringer Mannheim, Mannheim, Germany. Ref Type: Generic 21996.

24. Goldmann T, Vollmer E, Gerdes J: What's Cooking? Detection of Important Biomarkers in HOPE-Fixed, Paraffin-Embedded Tissues Eliminates the Need for Antigen Retrieval. Am J Pathol 2003, I63(6):2638-2640.

25. Hartmann G, Battiany J, Poeck H, Wagner M, Kerkmann M, Lubenow $\mathrm{N}$, Rothenfusser S, Endres S: Rational design of new CpG oligonucleotides that combine $B$ cell activation with high IFNalpha induction in plasmacytoid dendritic cells. Eur J Immunol 2003, 33(6): 1633-1641.

26. Gold P, Freedman SO: Demonstration of tumor-specific antigens in human colonic carcinomata by immunological tolerance and absorbtion techniques:. J Exp Med 1965, I 21:439-462.

27. Grunert F, Luckenbach GA, Haderlie B, Schwarz K, von Kleist S: Comparison of colon-, lung-, and breast-derived carcinoembryonic antigen and cross-reacting antigens by monoclonal antibodies and fingerprint analysis. Ann N Y Acad Sci 1983, 417:75-85.

28. Takeshita F, Leifer CA, Gursel I, Ishii KJ, Takeshita S, Gursel M, Klinman DM: Cutting edge: Role of Toll-like receptor 9 in CpG DNA-induced activation of human cells. J Immunol 200I, 167(7):3555-3558.

29. Platz J, Beisswenger C, Dalpke A, Koczulla R, Pinkenburg O, Vogelmeier $C$, Bals R: Microbial DNA induces a host defense reac- 
tion of human respiratory epithelial cells. J Immunol 2004, 173(2):1219-1223.

30. Medzhitov R: CpG DNA: security code for host defense. Nat Immunol 200I, 2(I): I5-16.

31. Park Y, Lee SW, Sung YC: Cutting Edge: CpG DNA inhibits dendritic cell apoptosis by up-regulating cellular inhibitor of apoptosis proteins through the phosphatidylinositide-3'-OH kinase pathway. J Immunol 2002, I 68(I):5-8.

32. Yi AK, Hornbeck P, Lafrenz DE, Krieg AM: CpG DNA rescue of murine B lymphoma cells from anti-lgM-induced growth arrest and programmed cell death is associated with increased expression of c-myc and bcl-xL. J Immunol 1996, I 57( I I):4918-4925

33. Decker T, Schneller F, Kronschnabl M, Dechow T, Lipford GB, Wagner $\mathrm{H}$, Peschel C: Immunostimulatory CpG-oligonucleotides induce functional high affinity IL-2 receptors on B-CLL cells: costimulation with IL-2 results in a highly immunogenic phenotype. Exp Hematol 2000, 28(5):558-568.

34. Decker T, Schneller F, Sparwasser T, Tretter T, Lipford GB, Wagner $\mathrm{H}$, Peschel C: Immunostimulatory CpG-oligonucleotides cause proliferation, cytokine production, and an immunogenic phenotype in chronic lymphocytic leukemia B cells. Blood 2000, 95(3):999-1006.

35. Smith JB, Wickstrom E: Antisense c-myc and immunostimulatory oligonucleotide inhibition of tumorigenesis in a murine B-cell lymphoma transplant model. J Natl Cancer Inst 1998, 90(15): II 146-II54.

36. Carpentier AF, Chen L, Maltonti F, Delattre JY: Oligodeoxynucleotides containing CpG motifs can induce rejection of a neuroblastoma in mice. Cancer Res 1999, 59(21):5429-5432.

37. Wooldridge JE, Ballas Z, Krieg AM, Weiner G]: Immunostimulatory oligodeoxynucleotides containing CpG motifs enhance the efficacy of monoclonal antibody therapy of lymphoma. Blood 1997, 89(8):2994-2998.

38. Tokunaga $T$, Yamamoto $H$, Shimada $S$, Abe H, Fukuda T, Fujisawa $Y$, Furutani $Y$, Yano $O$, Kataoka T, Sudo T: Antitumor activity of deoxyribonucleic acid fraction from Mycobacterium bovis BCG. I. Isolation, physicochemical characterization, and antitumor activity. I Natl Cancer Inst 1984, 72(4):955-962.

39. Ballas ZK, Rasmussen WL, Krieg AM: Induction of NK activity in murine and human cells by CPG motifs in oligodeoxynucleotides and bacterial DNA. J Immunol 1996, I 57(5): | 840-1845.

40. Nagai M, Masuzawa T: Vaccination with MCP-I cDNA transfectant on human malignant glioma in nude mice induces migration of monocytes and NK cells to the tumor. Int Immunopharmacol 200I, I(4):657-664.

41. Nokihara H, Yanagawa H, Nishioka Y, Yano S, Mukaida N, Matsushima K, Sone S: Natural killer cell-dependent suppression of systemic spread of human lung adenocarcinoma cells by monocyte chemoattractant protein-I gene transfection in severe combined immunodeficient mice. Cancer Res 2000, 60(24):7002-7007.

\section{Publish with Bio Med Central and every scientist can read your work free of charge}

"BioMed Central will be the most significant development for disseminating the results of biomedical research in our lifetime. "

Sir Paul Nurse, Cancer Research UK

Your research papers will be:

- available free of charge to the entire biomedical community

- peer reviewed and published immediately upon acceptance

- cited in PubMed and archived on PubMed Central

- yours - you keep the copyright

Submit your manuscript here:

http://www.biomedcentral.com/info/publishing_adv.asp
BiolMedcentral 